\title{
Using narrative in nursing research
}

Joyce M (2015) Using narrative in nursing research. Nursing Standard. 29, 38, 36-41.

Date of submission: March 24 2014; date of acceptance: June 122014.

\begin{abstract}
Narrative is a term used in everyday life. While it refers to a spoken or written account or story, it is also an increasingly popular research method. This article explores the role of narrative in nursing research and practice, and evaluates the use of narrative as a research method. Narrative is the study of how humans experience the world and how they interpret this experience. It can be an excellent research method to expand understanding of healthcare provision and individual patient experience.
\end{abstract}

\section{Author}

Maria Joyce Senior lecturer, College of Social Science, University of Lincoln, Lincoln, England.

Correspondence to:mjoyce@lincoln.ac.uk

\section{Keywords}

Narration, narrative, narrative ethics, narrative research, nursing research, patient experience, patients' stories

\section{Review}

All articles are subject to external double-blind peer review and checked for plagiarism using automated software.

\section{Online}

For related articles visit the archive and search using the keywords above. Guidelines on writing for publication are available at: journals.rcni.com/r/author-guidelines

NARRATIVE HAS A long literary tradition and is an increasingly popular concept in the health sciences. It has an acknowledged role in nursing practice, which is to acquire knowledge and understanding of the patient experience (Bailey and Tilley 2002, Hall and Powell 2011). Narrative may also be used as a method of qualitative research, which aims to interpret the meaning people attribute to their world and gain an understanding of it. Therefore, narrative is well suited to nursing research. Essentially, narrative in research is concerned with thinking about and studying 'told' stories. The terms narrative and storytelling may be used interchangeably where researchers seek to gain understanding by listening to individuals' stories. The individuals, who may be patients for whom nurses care, or participants in research, use their stories as a means to communicate experiences, such as a sequence of events in their lives, or a representation of themselves. Narrative may be both a research approach and the product of the research process. This article considers the role of narrative in nursing practice and evaluates it as a potential research method.

\section{Narrative in nursing}

In a healthcare culture focused on the patient perspective, patients' stories are increasingly relevant, and there is growing recognition of the relevance of narrative (Hawkins and Lindsay 2006). It is necessary to understand health experiences and the patient's story to meet the demand for high quality personalised services, providing patients with information and choice (Department of Health (DH) 2008, 2010, 2011, 2012). Moreover, individuals have their own views and opinions on health attainment and should be encouraged to increase their control of detrimental behaviours (DH 2010). Narrative can assist nurse researchers to gain an understanding of the patient perspective and how this may shape their experiences and behaviours (Bailey and Tilley 2002, Hall and Powell 2011).

Narrative occurs in the nurse-patient relationship in both clinical and therapeutic settings. Patients remember, recall and retell their stories when they talk about their experiences. Such stories serve as a window into the patient's world, through which nurses can gain valuable insight into what the story means to the patient (Hall and Powell 2011). Opportunities to gain insight from narrative might occur during the initial patient assessment and the routine provision of physical or psychological care (Gaydos 2005). Through storytelling, thoughts are structured and set in a framework of timelines and sequences of actions (Lieblich et al 1998). During this process, patients create meaning from their experience.

Narrative is also present in record-keeping in clinical practice. Writing up the patient assessment and care plan forms a structure that allows others to understand what has taken place (Bunker Rosdahl and Kowalski 2008). Verbal and written narratives in care planning and record-keeping may differ, with the written narrative being used to relate information and the verbal account 
providing context and meaning. In essence, narrative refers to the told stories of our lives and the lives of others.

It has been suggested that the move towards a more technically focused profession might have occurred at the expense of caring and compassion in nursing (Holloway and Freshwater 2007a). These concerns were addressed in Compassion in Practice: Nursing, Midwifery and Care Staff. Our Vision and Strategy (DH 2012), which instructs all nurses to embrace qualities known as the 6Cs, including care, compassion and communication. The $6 \mathrm{Cs}$ encourage better listening in communications between nurses, patients and their families. They also underpin improved planning for individualised care and shared decision making. As a research method, narrative provides a formal, measurable framework with which to add context to a story (Denzin 1989), supporting good communication and relationships between patients, their families and the nursing staff responsible for planning and delivering care.

Narrative is often used therapeutically to help patients and service users come to terms with their illness, through talking about their experiences of health and ill health (Holloway and Freshwater 2007b). The act of forming an illness narrative may be therapeutic and form part of a coping strategy (Hardcastle et al 2007). Narrative may also be used to make sense of and explain the experience of living with illness to oneself and to others (Weingarten 2011). Mental health nursing uses narrative in this way, with the storyteller relaying information to health professionals relating to his or her experience of ill health and the effect it has on their life (Kettles et al 2009). Websites and blogs also use personal stories and interviews to provide knowledge and information. Their purpose may be catharsis and they may assist the reader or listener to understand illness in terms of how others experience it (Mind 2008, Diabetes UK 2012, Macmillan Cancer Support 2015). These stories may be provided informally by individuals or patient groups, or they may be used formally by healthcare and other agencies. Narratives may be therapeutic, educational and knowledge-enhancing for those telling and listening. Crucially, they also allow researchers to access individual experience of illness.

Narrative researchers are interested in patient experience of illness and other life events. Knowledge gathered from the nurse-patient enquiry or the research interaction is used to record the story, its context, timeline and flow and to attempt to capture the meaning embedded in the participant story. Narrative is open to collaborative interpretation between the storyteller and listener. The stories are socially constructed, in that they come out of the social world in which the storyteller lives, and we understand them in relation to our own level of social experience and knowledge. Exploring narrative through interpretive research allows access to the individual and their experiences, via their socially constructed stories.

\section{Narrative as a research method}

Narrative is a many-faceted concept that can be difficult to define. It may be the approach or the method and does not fit any neat categories. In storytelling, the participant's told story is presented in a variety of ways. Narrative may relate to the research method, the phenomenon and the process, or just the phenomenon (Clandinin and Connelly 2000, Pinnegar and Daynes 2006). Narrative may refer to the participant telling their story, but it may also describe the story that is being told; it is an individual research method as well as a means of delivering an individual's story.

Narrative is socially constructed and may be personal and focus on the individual, or narrate social histories, myths and stories to explain behaviour or context (Polkinghorne 1988). Narrative concerns 'events perceived by the speaker as important... selected, organised, connected and evaluated as meaningful for a particular audience' (Kohler Riessman 2008). It may be defined as first order, telling the individual's story, or as second order, giving the researcher's account of other stories (Carr 1997).

The presentation of narrative is generally linear, beginning in a certain place and moving forward logically, with a beginning, middle and end (Denzin 1989). When we structure a story, we introduce it, we narrate the main body of the story and finally we conclude it, filling the sections out with a range of information. The story is shaped by the narrator through the telling, in a way that makes sense to them. This narration may not exactly match the sequence in which it was experienced; it presents a neat and tidy version of the story, occasionally in stark contrast to the real-life experiences it describes (Sikes 2000). When we, as storytellers, reflect on experiences, we structure and order them in a way that makes them logical and meaningful, both to us and those to whom we are telling the story. The story may be constructed with the listener, as the listener asks questions and the teller responds, or it may develop as a self-narrative, with no input from the listener after the first enquiry sets the context.

Narrative is an interpretive approach in the qualitative research paradigm. Interpretive research attempts to enter the social world of those who are being researched to gain understanding 
of phenomena and to interpret them (Silverman 2006). An interpretative approach refers to one where the data are actually our representation of others people's representations (Geertz 1973).

\section{Narrative approaches}

Narrative research may use a variety of approaches, including life history, life incidents, storytelling, biography and autobiography (Letherby 2003). These approaches have similar features and may overlap: while they differ by definition, each method might carry a trace of the others (Denzin 1989).

\section{Life history}

Life history emerged from the earlier disciplines of biography and autobiography, presenting new information on how people lived, their influences and values (Burgess 1984, Goodson and Sikes 2001, Silverman 2006, 2011). Life history may be limited to particular life events or experiences and may include the study of life documents, including photographs, poems, certificates, emails, letters, art and video recordings; or individual interviews, where the participant reflects and recollects as they move backwards and forwards in recalling experiences and events. Life history research is often used in emancipatory research studies, presenting individual stories of the disempowered or vulnerable (Josselson and Lieblich 1993).

\section{Life incidents}

Life incident research relates to human experiences and events that affect an individual's life.

Denzin (1989) describes these as turning points, or epiphanies, that may alter the structure of a person's life, and outlines how they may have different levels of significance. They may be positive or negative, may arise from crisis or change and may present in a variety of forms. However, they all receive their meaning retrospectively. While life incidents provide information on events that have altered the life of an individual, they are also embedded in a social context, representing life experience subject to the social and political influences of that time.

\section{Storytelling}

Storytelling is a means by which individuals tell others about themselves, their experiences and thoughts. The individual defines meaning by the story that is told and the form in which it is told, validating the story through its creation (Berger and Quinney 2004). Storytelling is a narrative feature in which the individual can tell their story, their way (Holloway and Freshwater 2007a). It can be further defined as 'self-stories', which are personal narratives and contextually specific (Denzin 1989). These self-stories are ones that evolve through the telling; they do not exist independently before the telling, but once told, can take on the status of a story that can be retold (Denzin 1989). According to Denzin (1989), all stories are 'open ended, inconclusive and ambiguous' and 'subject to multiple interpretations'.

\section{Biography}

Biography is a unique narrative record of an individual's life, often chosen to record major life events (Denzin 1989). The biographical approach collates information to provide an overview of the life of individual, using their life history and including the context in which they experienced it. Biography includes sub-categories of individual biography, autobiography, life history and oral history (Hagermaster 1992, Creswell 1998). These are often placed within a typology of narrative, a type of narrative with similar features (Holloway and Freshwater 2007a). Creswell (2003) describes how the biographical approach centres on the individual and his or her life.

\section{Autobiography}

Autobiography is an approach that focuses on the individual and their personal experiences and perceptions. Through autobiography, individuals connect the present with the past and the future, and present their own account of their life (Holloway and Freshwater 2007a). Recall and reconstruction of memories are key features of autobiographical research. As such, this is a self-told story, 'construed and reconstrued' and an interpretation, rather than information on a life lived (Bruner 1995). Autobiography can also elucidate social processes through the presentation of the past.

\section{Designing a narrative research study}

As in all research design, narrative research is influenced by the philosophical basis of the research study, which informs the choice of research questions, method and methodology (Grix 2010). Our philosophical position affects and influences our choice of methodological approach, influenced by our epistemology and ontology. Our ontological position refers to how we perceive the world and how things are (Crotty 1998). Our epistemological assumptions arise from how we see the world in terms of knowledge, how we know what we know, and how we believe knowledge is acquired (Creswell 1998). We have presumptions of what our world looks like, we have our own individual views and interpret our social reality in particular ways. These presumptions influence the way we develop research design and methodology. 


\section{Choosing a sample}

There are several strategies for developing a sample, but purposeful sampling is the one most often used in qualitative research (Patton 2002, Silverman 2005). This involves obtaining a sample from a particular group of people that have common characteristics. The group may be further bound by age, gender, time, location, employment or many other variables, all of which make them typical cases. There is no restrictive rule on sample size and, while the size of sample may be quite small in qualitative research, this is not always the case. The sample size should generate sufficient in-depth, textually rich data to answer the research question.

\section{Collecting data}

Data in qualitative research may be collected through interview, focus groups, textual or visual analysis, observation or action research. The most common method is interview, either on a one-to-one basis or in focus groups. Interviews may follow a planned structured, semi-structured or unstructured format (Silverman 2011). The format chosen should be one that will generate suitable data to answer the research question.

\section{Measuring quality}

Several frameworks are available to ensure quality in a qualitative research study. Lincoln and Guba (1985) give examples, providing stages to be worked through, from determining the focus and checking for paradigm fit to ensuring trustworthiness and auditability. These frameworks address elements such as credibility, dependability, confirmability, transferability and authenticity. There are steps that can be taken to improve validity; Mays and Pope (1996) provide a detailed account of these, using triangulation, respondent validation, clear exposition of methods of data collection and analysis, reflexivity, attention to negative cases and fair dealing. A detailed audit trail should be provided, alongside descriptive methodology to assure the readership that the findings could be repeated if the study were repeated with similar participants, in a similar context (Lincoln and Guba 1985). The study should accurately represent the data provided by the participants and describe if and how it could be transferred to other settings or groups (Lincoln and Guba 1985). Finally, the way in which the study meets ethical guidelines for good research practice should be identified and explained (British Educational Research Association 2011, Health Research Authority 2011).

Truth, trustworthiness and reliability are common concerns in narrative research (Holloway and Freshwater 2007a). How can the researcher trust the participant is telling the truth and telling the whole story? Participant inaccuracy may be the result of unreliable memory or misunderstanding, rather than deliberate deception (Joyce 2012). Omissions might be a result of the participant assuming researcher familiarity with the topic (Burgess 1984). Narratives containing deliberate lies do not lack merit entirely, because 'even when lying, storytellers illuminate aspects of their world because they lie for a reason' (Holloway and Freshwater 2007a). Exaggeration and distortion might be caused by the participant's subconscious or conscious need to reconstruct the event or reposition themselves in the story (Holloway and Freshwater 2007b).

Researchers who wish to conduct or commission research involving people must first apply for approval through the relevant ethical approval bodies, such as the British Educational Research Association (2011) and the Health Research Authority (2011). The research proposal must be evaluated and approved by the appropriate research committee before research begins. The research design should also meet the guidelines set by the organisation or body concerned to ensure the research is ethical, safe and high quality.

\section{Data analysis and interpretation}

Data analysis is the process through which the gathered data are structured and organised, by identifying, labelling and coding. The first step in examining the data is familiarisation with its content. This occurs through listening, reading, re-reading and transcribing data and by addition of field notes and indexing. The data should be broken down and rearranged systematically, to allow examination for ideas and themes. Data analysis may be supported by electronic data management systems, which enable the researcher to analyse quickly and accurately textual and visual research data with a clear audit trail, or it may be performed manually by the researcher. Both methods have strengths and weaknesses (Welsh 2002). The analysis and interpretation of data are separate processes. Analysis involves the selection and ordering of data into categories, while interpretation involves attaching meaning to the analysis. Analysis may be undertaken using content analysis (Mishler 1986, Elliott 2005), narrative analysis (Morse and Field 1996, Silverman 2006, Denscombe 2007) or other methods, such as thematic, structural, interactional and performative analyses (Kohler Reissman 2008). Whichever method of analysis is chosen, it must fit the aims and philosophical basis of the research study.

Data interpretation is closely associated with analysis. An in-depth consideration of the data identifies the social, structural and psychological processes surrounding the data. Interpretation is 
achieved by knowing the data and the context of data collection, thorough coding and looking for connections and contradictions, linking to the literature and the original ideas that prompted the research and finally, by identifying concepts (Pole and Lampard 2002). Identifying concepts involves moving through an inductive process, in which the researcher makes decisions about significance, patterns, meaning and propositions; reduces data and draws conclusions (Miles and Huberman 1994). The developing theory is supported by accurate recording of the data collection and analysis, presenting findings in an open and traceable way, with a clear audit trail. The findings should be presented in a way that reflects the aims of the study.

\section{Presenting narrative}

The narrative can be presented in written form, giving an interpreted account of the analysed findings supported by individual quotes to reinforce meaning. This written account of the data is what Czarniawska (2004) terms representation of the story, that is the story recorded, interpreted and 're-storied'. Holloway and Freshwater (2007a) describe researchers as 'the sculptors of the final piece of writing'. Meaning 'must be captured', while the participant narrative must 'resonate in the reader and give a sense of location' (Holloway and Freshwater 2007a).

Other forms of research presentation include poetry, plays, video and audio clips, each with individual strengths and weaknesses. The choice of either performance or written approach must be carefully considered, because the written form may not always be best for projecting emotional content. Prendergast (2009) explores the value of poetry in qualitative research and how it has the power to express understanding and move and enlighten the reader. Drama, dance, music, photography and other visual art forms may also enable individuals to express their story (Prendergast 2003). These performance forms might be presented without researcher commentary, leaving them open to interpretation. Alternatively, they may be accompanied by ongoing or partial commentary to aid understanding. Whether we are listening to or transcribing words or viewing photographs, we are interpreting them, gaining insight and creating meaning with the narrator (Huberman and Miles 2002).

\section{Conclusion}

Narrative is a powerful genre that can be challenging to define and categorise. However, ultimately this is also its strength. Narrative is the story and may also be the method. There are several approaches that can be used in the narrative genre. These may at times overlap, but in this way they can enhance the richness of gathered data. The story that generates the data may be presented as a sequence of events or as a story that represents the self. Understanding develops through interpretation of the story. Narrative research is a method that lends itself to layering knowledge in a sequential way. This enables the researcher to form a holistic view of the participant's social world and the meaning they attach to their life experiences. The researcher's philosophical and theoretical bases are crucial in designing research studies using narrative, because to create meaning from the stories of others, we should understand how we as individuals view the world. Narrative is the study of how humans experience the world and how this experience is interpreted by them. It is valuable in the nurse-patient relationship and can be an excellent research method with which to discover meaning in healthcare provision and individual patient experience NS

\section{Acknowledgement}

Nursing Standard wishes to thank Leslie Gelling, reader in nursing at Anglia Ruskin University, for co-ordinating and developing the Research series.

\section{References}

Bailey PH, Tilley S (2002) Storytelling com/nnpafex (Last accessed: and the interpretation of meaning in qualitative research. Journal of Advanced Nursing. 38, 6, 574-583.

Berger R, Quinney R (2004) The Narrative Turn in Social Inquiry: Toward a Storytelling Sociology. Paper presented at the annual meeting of the American Sociological Association. August 14, San Francisco CA. tinyurl.
April 28 2015.)

British Educational Research Association (2011) Ethical Guidelines for Educational Research. tinyurl.com/ldk4578 (Last accessed: April 28 2015.)

Bruner J (1995) The autobiographical process. Current Sociology. 43, 2, 161-177.
Bunker Rosdahl C, Kowalski MT (2008) Textbook of Basic Nursing. Ninth edition. Lippincott, Williams and Wilkins, Philadelphia PA.

Burgess RG (1984) In the Field: An Introduction to Field Research. Routledge, Abingdon.

Carr D (1997) Narrative and the real world: an argument for continuity. In Hinchman LP,
Hinchman SK (Eds) Memory, Identity and Community: The Idea of Narrative in the Human Sciences. State University of New York Press, Albany NY, 7-25.

Clandinin DJ, Connelly FM (2000) Narrative Inquiry: Experience and Story in Qualitative Research. Jossey-Bass, San Francisco CA. 
Creswell JW (1998) Qualitative Inquiry and Research Design: Choosing Among Five Traditions. Sage Publications, Thousand Oaks CA

Creswell JW (2003) Research Design: Qualitative, Quantitative, and Mixed Methods Approaches. Second edition. Sage Publications, Thousand Oaks CA.

Crotty M (1998) The Foundations of Social Research. Sage

Publications, London.

Czarniawska B (2004) Narratives in Social Science Research. Sage Publications, London.

Denscombe M (2007) The Good Research Guide: For Small-Scale Social Research Projects. Open University Press, Buckingham.

Denzin NK (1989) Interpretive Biography. Sage Publications, Thousand Oaks CA.

Department of Health (2008) High Quality Care for All. NHS Next Stage Review Final Report. tinyurl. com/lvxvmpu (Last accessed: April 28 2015.)

Department of Health (2010) Healthy Lives, Healthy People: Our Strategy for Public Health in England. The Stationery Office, London.

Department of Health (2011) Caring for Our Future. Shared Ambitions for Care and Support. tinyurl.com/krr4qx6 (Last accessed: April 28 2015.)

Department of Health (2012) Compassion in Practice: Nursing, Midwifery and Care Staff. Our Vision and Strategy. tinyurl. com/c5lc4n2 (Last accessed: April 28 2015.)

Diabetes UK (2012) Local Support Groups. tinyurl.com/003s5py (Last accessed: April 28 2015.)

Elliott J (2005) Using Narrative in Social Research: Qualitative and Quantitative Approaches. Sage Publications, London.

Gaydos HL (2005) Understanding personal narratives: an approach to practice. Journal of Advanced Nursing. 49, 3, 254-259.

Geertz C (1973) Thick description: toward an interpretive theory of culture. In Geertz C (1973) The Interpretation of Cultures. Basic Books, New York NY, 3-30.

Goodson I, Sikes P (2001) Life History Research in Educational Settings: Learning from Lives. Open University Press, Buckingham.

Grix J (2010) The Foundations of Research. Second edition. Palgrave Macmillan, Basingstoke.

Hagermaster JN (1992) Life history: a qualitative method of research. Journal of Advanced Nursing. 17, 9, 1122-1128.

Hall JM, Powell J (2011) Understanding the person through narrative. Nursing Research and Practice. doi:10.1155/2011/293837.

Hardcastle M, Kennard D, Grandison S, Fagin L (2007) Experiences of Mental Health In-Patient Care: Narratives From Service Users, Carers and Professionals. Routledge, Hove.

Hawkins J, Lindsay E (2006) We listen but do we hear? The importance of patient stories. British Journal of Community Nursing. 11, 9, S6-S14.

Health Research Authority (2011) Research Ethics Committee. tinyurl.com/p3d3alj (Last accessed: April 28 2015.)

Holloway I, Freshwater D (2007a) Narrative Research in Nursing. Blackwell Publishing, 0xford.

Holloway I, Freshwater D (2007b) Vulnerable story telling narrative research in nursing. Journal of Research in Nursing. 12, 6, 703-711.

Huberman AM, Miles MB (2002) The Qualitative Researcher's Companion: Classic and Contemporary Readings. Sage Publications, Thousand Oaks CA.
Josselson R, Lieblich A (Eds) (1993) The Narrative Study of Lives. Sage Publications, Newbury Park CA.

Joyce M (2012) Towards an understanding of career progression for female professors of nursing: a small scale study. Unpublished EdD thesis, University of Lincoln, Lincoln.

Kettles AM, Woods P, Collins M (2009) Therapeutic Interventions for Forensic Mental Health Nurses. Jessica Kingsley Publishers, London.

Kohler Reissman C (2008) Narrative Methods for the Human Sciences. Sage Publications, Thousand Oaks CA.

Letherby G (2003) Feminist Research in Theory and Practice. Open University Press, Buckingham.

Lieblich A, Tuval-Mashiach R, Zilber T (1998) Narrative Research: Reading, Analysis, and Interpretation. Sage Publications, Thousand Oaks CA.

Lincoln YS, Guba EG (1985)

Naturalistic Inquiry. Sage Publications, Newbury Park CA.

Macmillan Cancer Support (2015) Find Groups Near You. tinyurl. com/qasq2qo (Last accessed: April 28 2015.)

Mays N, Pope C (1996) Rigour and qualitative research. In Mays N, Pope C (Eds) Qualitative Research in Health Care. BMJ Publishing Group, London, 50-52.

Miles M, Huberman AM (1994) Qualitative Data Analysis: An Expanded Sourcebook. Second edition. Sage Publications, Thousand Oaks CA.

Mind (2008) Time to Change. www.time-to-change.org.uk/ (Last accessed: April 28 2015.)

Mishler EG (1986) Research Interviewing: Context and Narrative. Harvard University Press, Cambridge MA.

Morse JM, Field PA (1996) Nursing Research. The Application of Qualitative Approaches. Second edition. Nelson Thornes, Cheltenham.
Patton MQ (2002) Qualitative Research and Evaluation Methods. Third edition. Sage Publications, Thousand Oaks CA.

Pinnegar S, Daynes JG (2006) Locating narrative inquiry historically: thematics in the turn to narrative. In Clandinin DJ (Ed) Handbook of Narrative Inquiry: Mapping a Methodology. Sage Publications, Thousand Oaks CA, 3-34.

Pole C, Lampard R (2002) Practical Social Investigation: Qualitative and Quantitative Research in the Social Sciences. Prentice Hall, Harlow.

Polkinghorne DE (1988) Narrative Knowing and the Human Sciences. State University of New York Press, Albany NY.

Prendergast M (2003) I, Me, Mine: Soliloquizing as Reflective Practice. International Journal of Education and the Arts. 4, 1 www.ijea.org/ v4nl/ (Last accessed: April 28 2015.)

Prendergast M (2009) "Poem is what?" Poetic inquiry in qualitative social science research. International Review of Qualitative Research. 4, 1, 541-568.

Sikes P (2000) Truth and lies revisited. British Educational Research Journal. 26, 2, 257-270.

Silverman D (2005) Doing Qualitative Research: A Practical Handbook. Second edition. Sage Publications, Thousand Oaks CA.

Silverman D (2006) Interpreting Qualitative Data: Methods for Analyzing Talk, Text and Interaction. Third edition. Sage Publications, London.

Silverman D (Ed) (2011) Qualitative Research: Theory, Method and Practice. Sage Publications, London.

Weingarten K (2011) Making sense of illness narratives: braiding theory, practice and the embodied life. tinyurl.com/pj4z3x9 (Last accessed: April 28 2015.)

Welsh E (2002) Dealing with data: using NVivo in the qualitative data analysis process. Forum Qualitative Social Research. 3, 2, Article 26. 